\title{
Hydrogen-Induced Cracking of Drip Shield
}

S.C. $\mathrm{Lu}$

\section{August 1, 1999}

U.S. Department of Energy

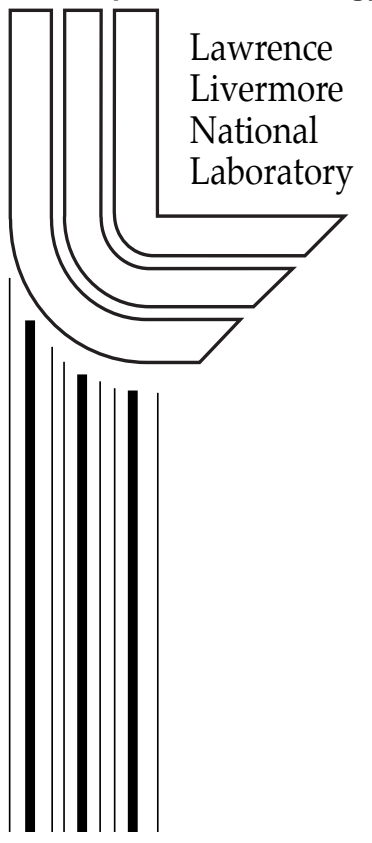




\section{DISCLAIMER}

\section{\$}

This document was prepared as an account of work sponsored by an agency of the United States Government. Neither the United States Government nor the University of California nor any of their employees, makes any warranty, express or implied, or assumes any legal liability or responsibility for the accuracy, completeness, or usefulness of any information, apparatus, product, or process disclosed, or represents that its use would not infringe privately owned rights. Reference herein to any specific commercial product, process, or service by trade name, trademark, manufacturer, or otherwise, does not necessarily constitute or imply its endorsement, recommendation, or favoring by the United States Government or the University of California. The views and opinions of authors expressed herein do not necessarily state or reflect those of the United States Government or the University of California, and shall not be used for advertising or product endorsement purposes.

\section{\$}

ork performed under the auspices of the U. S. Department of Energy by the University of California Lawrence Livermore National Laboratory under Contract W-7405-Eng-48.

$\$$

\$his report has been reproduced

irectly from the best available copy.

\$

vailable to DOE and DOE contractors from the

ffice of Scientific and Technical Information

取O. Box 62, Oak Ridge, TN 37831

取ices available from (423) 576-8401

14ttp: / / apollo.osti.gov/bridge/

\$

vailable to the public from the

ational Technical Information Service

W.S. Department of Commerce

285 Port Royal Rd.,

\$pringfield, VA 22161

1 ttp: / / www.ntis.gov/

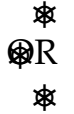

\$awrence Livermore National Laboratory

\$echnical Information Department's Digital Library

\$ttp://www.llnl.gov/tid/Library.html

\$ 


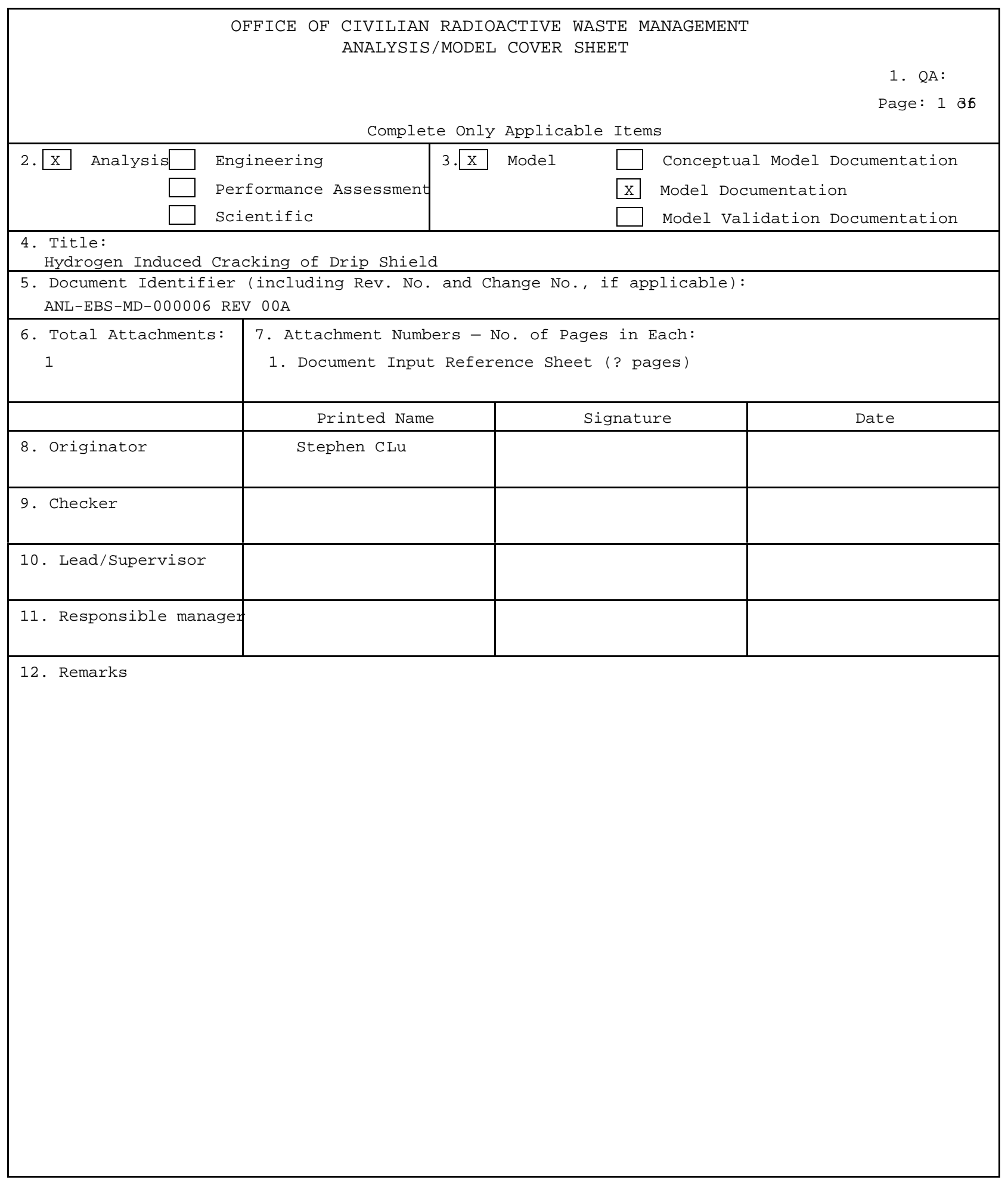


OFFICE OF CIVILIAN RADIOACTIVE WASTE MANAGEMENT ANALYSIS/MODEL REVISION RECORD

1. Page: 2 of

Complete Only Applicable Items

2. Analysis or Model Title:

Hydrogen Induced Cracking of Drip Shield

3. Document Identifier (including Rev. No. and Change No., if applicable):

ANL-EBS-MD-000006 REV 00A

4. Revision/Change No. 5. Description of Revision/Change 


\section{CONTENTS}

Page

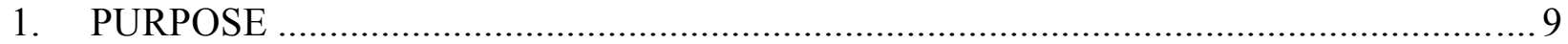

2. QUALITY ASSURANCE …...................................................................... 11

3. COMPUTER SOFTWARE AND MODEL USAGE ................................................... 13

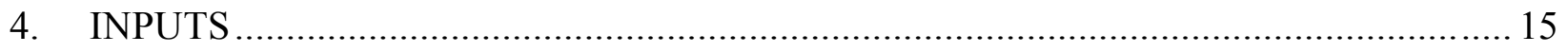

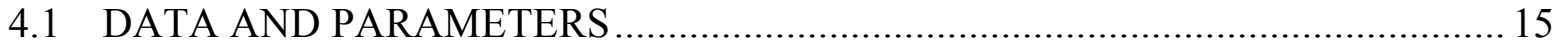

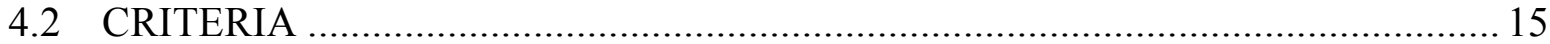

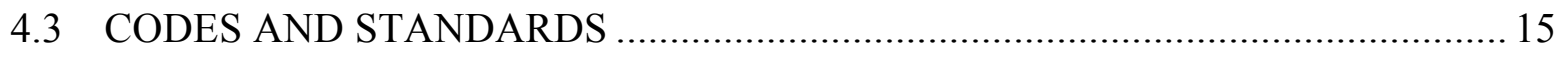

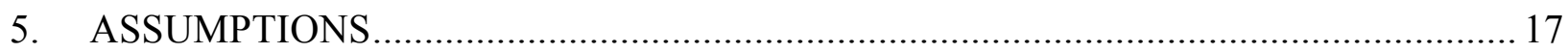

6. ANALYSIS/MODEL ............................................................................................. 19

6.1 DESCRIPTION OF MODEL FOR HYDROGEN INDUCED CRACKING ............. 19

6.2 APPLICATION OF HIC MODEL TO DRIP SHIELD ....................................... 25

6.2.1 Material ........................................................................................... 25

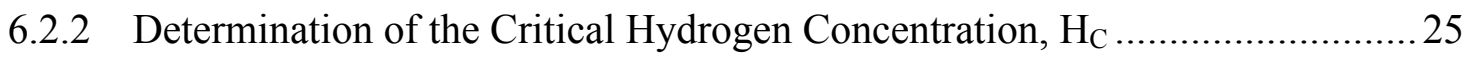

6.2.3 Determination of Hydrogen Concentration................................................26

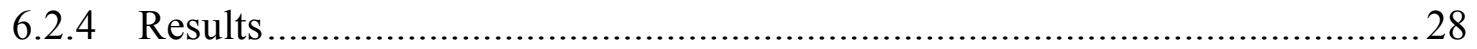

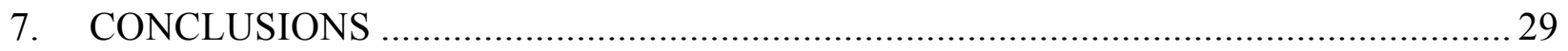

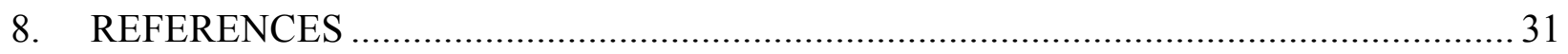

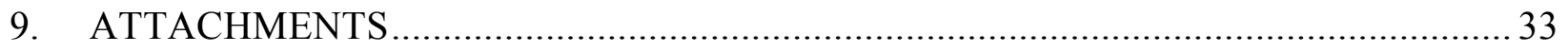


INTENTIONALLY LEFT BLANK 


\section{FIGURES}

Page

1. Schematic showing the combinations of stress intensity factor and hydrogen

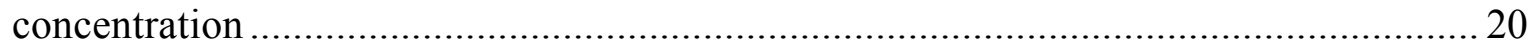

2. Hydrogen concentration versus Econt at locations away from the primary fracture .........27

3. SIMS depth profiles for hydrogen in Ti-16 (60oC, SDW, 1 year, aqueous phase) .......... 27 
INTENTIONALLY LEFT BLANK 


\section{ACRONYMS AND ABBREVIATIONS}

\begin{tabular}{|c|c|}
\hline AMR & Analyses and Models Report \\
\hline CRWMS & Civilian Radioactive Waste Management System \\
\hline DS & drip shield \\
\hline $\mathrm{HIC}$ & hydrogen induced cracking \\
\hline LLNL & Lawrence Livermore National Laboratory \\
\hline LTCTF & Long Term Corrosion Test Facility \\
\hline $\mathrm{M} \& \mathrm{O}$ & Management and Operating Contractor \\
\hline PMR & Process Model Report \\
\hline QAP & Quality Administrative Procedure \\
\hline QARD & Quality Assurance Requirements and Description \\
\hline QP & Quality Procedure \\
\hline SCC & stress corrosion cracking \\
\hline $\mathrm{SCE}$ & saturated calomel electrode \\
\hline $\mathrm{SCW}$ & simulated concentrated water \\
\hline SDW & simulated dilute water \\
\hline SIMS & secondary ion mass spectrometry \\
\hline SSRT & slow strain rate test \\
\hline WP & waste package \\
\hline WPD & waste package degradation \\
\hline YMP & Yucca Mountain Site Characterization Project \\
\hline
\end{tabular}


INTENTIONALLY LEFT BLANK 


\section{PURPOSE}

The most likely failure mechanism for titanium and its alloys under waste disposal conditions is via the process of hydrogen absorption leading to hydrogen-induced cracking (HIC). HIC is also called hydrogen embrittlement, which is a process resulting in a decrease of fracture toughness or ductility of a metal due to the presence of atomic hydrogen. The decrease of fracture toughness can cause the premature brittle fracture of a normally ductile material under sustained load.

The purpose of the process-level model is to account for the HIC effects on the drip shield (DS), which is assumed to be Titanium Grade 7 (Ti-7) [UNS R52400]. This Analyses and Models Report (AMR) serves as a feed to the Waste Package Degradation (WPD) Process Model Report (PMR).

Understanding the degradation of the DS due to HIC is key to one of the most important principal factors in repository performance - the premature failure of the DS. This failure is caused by the decrease in fracture toughness of the DS material due to HIC. This AMR proposes a realistic model to account for the degradation of the DS due to the effects of HIC, based upon data generated by the project. 
INTENTIONALLY LEFT BLANK 


\section{QUALITY ASSURANCE}

This document was prepared in accordance with the Civilian Radioactive Waste Management System (CRWMS) Management and Operating Contractor (M\&O) Quality Administrative Procedures (QAPs). The information provided in the document is to be indirectly used in the evaluation of the Monitored Geologic Repository waste package and engineered barrier segment. The waste package and engineered barrier segment have been identified as items important to radiological safety and waste isolation in the QAP-2-3 evaluation entitled Classification of the Preliminary MGDS Repository Design (CRWMS M\&O 1999a p. VI-11). The Waste Package Operations responsible manager has evaluated the document development activity in accordance with QAP-2-0 Conduct of Activities. The Activity Evaluation Neutronics Methodology - SR (CRWMS M\&O 1999b) evaluation has determined the preparation review of the document is subject to Quality Assurance Requirements and Description (QARD) (DOE 1999) controls. There is no determination of importance evaluation developed in accordance with Nevada Line Procedure, NLP-2-0, since the document does not involve any field activity. This AMR has been developed in accordance with the Yucca Mountain Site Characterization Project Procedure entitled, Analyses and Models (AP-3.10Q, Revision 0, ICN 0). 
INTENTIONALLY LEFT BLANK 


\section{COMPUTER SOFTWARE AND MODEL USAGE}

No computer software or models have been used to support the development of the analysis and modeling activities described in this AMR. 
INTENTIONALLY LEFT BLANK 


\section{INPUTS}

\subsection{DATA AND PARAMETERS}

Input for this AMR includes data for the critical hydrogen concentration $\left(\mathrm{H}_{\mathrm{C}}\right)$ and the measured hydrogen concentration of various grades of titanium alloys. $\mathrm{H}_{\mathrm{C}}$ values were obtained from a review paper compiled by Shoesmith (1999) for the YMP. Data for hydrogen concentration were obtained from results of tests conducted at LLNL for YMP (Roy et al. 1999 and Bedrossian 1999).

\subsection{CRITERIA}

The criteria applicable to this AMR are stated in Section 1.2, "System Design Criteria," of the Uncanistered Spent Nuclear Fuel Disposal Container System Description Document (CRWMS 1999c).

"The disposal container shall be designed such that no more than 1 percent of all waste packages breach during the first 1,000 years after emplacement (breaching is defined as an opening through the wall of the waste package through which advective or diffusive transport of gas or radionuclides can occur)." (Section 1.2.1.1)

"The disposal container shall be designed such that for 10,000 years after permanent closure of the repository the release rate of any radionuclide from all waste packages shall not exceed one part in 100,000 per year of the inventory of that radionuclide calculated to be present at 1,000 years following permanent closure; provided, that this requirement does not apply to any radionuclide which is released at a rate less than 0.1 percent of the calculated total release rate limit. The calculated total release rate limit shall be taken to be one part in 100,000 per year of the inventory of radioactive waste, originally emplaced in the underground facility, that remains after 1,000 years of radioactive decay." (Section 1.2.1.4)

The analysis contained in this AMR ensures the integrity of the DS design such that the design criteria for the waste packages will not be compromised.

\subsection{CODES AND STANDARDS}

No codes or standards were used to perform the analysis or to develop the model for this AMR. 
INTENTIONALLY LEFT BLANK 


\section{ASSUMPTIONS}

The following assumptions are made to perform the analysis and to develop the model for this AMR:

1. The basic premise in the model is that failure will occur once the hydrogen content exceeds a certain limit or critical value, HC. This model is very conservative because it assumes that, once the environmental and material conditions can support that particular corrosion process, failure will be effectively instantaneous. Clearly, the propagation of a localized corrosion process, whether it be a pit, a crevice, a stress corrosion crack or a hydrogen-induced crack, does not proceed instantaneously to failure. However, if the rate of propagation is fast (per the geologic time scales being considered) then the process can be thought of as instantaneous; e.g., 30 years of "slow" crack growth is irrelevant on a time scale of 103 to 105 years.

2. Another factor ignored in this analysis is the impact of propagation-limiting processes. For example, with a pit or crevice, repassivation may occur; or with a stress corrosion crack, crack blunting could occur. In this HIC model, no crack initiation or crack blunting processes are considered.

3. The passive oxide is assumed to be permeable to hydrogen. Within a Canadian waste vault, this is a point for discussion. However, under Yucca Mountain conditions, the probability of hydrogen absorption occurring is much lower. For the purpose of this analysis, once this process becomes possible it is conservatively assumed that the oxide is rendered permeable to hydrogen, which then has free access to the alloy; i.e., any hydrogen entering the oxide can be rapidly transported to the metal.

4. Once in the alloy, the hydrogen is transported throughout the entire thickness of the material to yield a uniform distribution of hydrogen. In other words, transport processes within the alloy are rapid compared to the rate of absorption.

5. Data for the critical hydrogen concentration are not available for Ti-7. It is assumed the data available for other grades of titanium are also applicable to Ti-7, and bounding values are used for conservative purpose. 
INTENTIONALLY LEFT BLANK 


\section{ANALYSIS/MODEL}

\subsection{DESCRIPTION OF MODEL FOR HYDROGEN INDUCED CRACKING}

The most likely failure mechanism for titanium and its alloys under waste disposal conditions is via the process of hydrogen absorption leading to hydrogen-induced cracking (HIC). HIC is also called hydrogen embrittlement, which is a process resulting in a decrease of fracture toughness or ductility of a metal due to the presence of atomic hydrogen. The usual failure mode for a ductile material is the ductile tearing observed during slow crack growth. The decrease of fracture toughness can cause the fast crack growth (brittle fracture) of a normally ductile material under sustained load. During slow crack growth, material will fail as the stress intensity factor K reaches a value $\mathrm{K}_{\mathrm{S}}$. During fast crack growth, the same material will fail as the stress intensity factor $\mathrm{K}$ reaches a value $\mathrm{K}_{\mathrm{H}}$, which is less than $\mathrm{K}_{\mathrm{S}}$.

Generally, the passive oxide film on titanium (Ti) acts as an excellent barrier to the transport of hydrogen through the oxide, and hydrogen absorption under open-circuit (i.e., natural corrosion) conditions would not be expected and is generally not observed. The concern remains, however, that over normal operating periods (up to tens of years), the process of hydrogen absorption may have been too slow to observe analytically, and that, over the course of many years $\left(10^{3}\right.$ to $\left.10^{5}\right)$, this absorption could lead to a significant accumulation of hydrogen and the danger of HIC.

Modeling HIC could become extremely complicated, involving an attempt to determine the influences of both the corrosion processes and the presence of tensile stresses on such processes. There would be little chance of incorporating such a model into a full-scale performance assessment. The primary drawbacks would be the absence of a meaningful stress analysis, which could be applied to the problem, and a lack of definition on how a crack would start and propagate.

Under Canadian waste vault conditions a very simple approach was adopted to predict when HIC might become a potential failure process in a waste container (Shoesmith et al. 1995). In essence, this model is a susceptibility model, or the equivalent of an initiation model for localized corrosion processes such as pitting and crevice corrosion. The basic premise of the model is that failure will occur once the hydrogen content exceeds a certain limit or critical value, $\mathrm{H}_{\mathrm{C}}$. Figure 1 represents, schematically, the combinations of stress intensity factor and hydrogen concentration leading to (1) fast crack growth (brittle fracture, $\left.\mathrm{K}_{\mathrm{H}}\right)$, (2) slow crack growth $\left(\mathrm{K}_{\mathrm{S}}\right)$ due to either sustained load cracking or ductile rupture, or (3) no failure.

This model is very conservative because it assume that, once the environmental and material conditions can support the particular corrosion process, failure will be effectively instantaneous. 


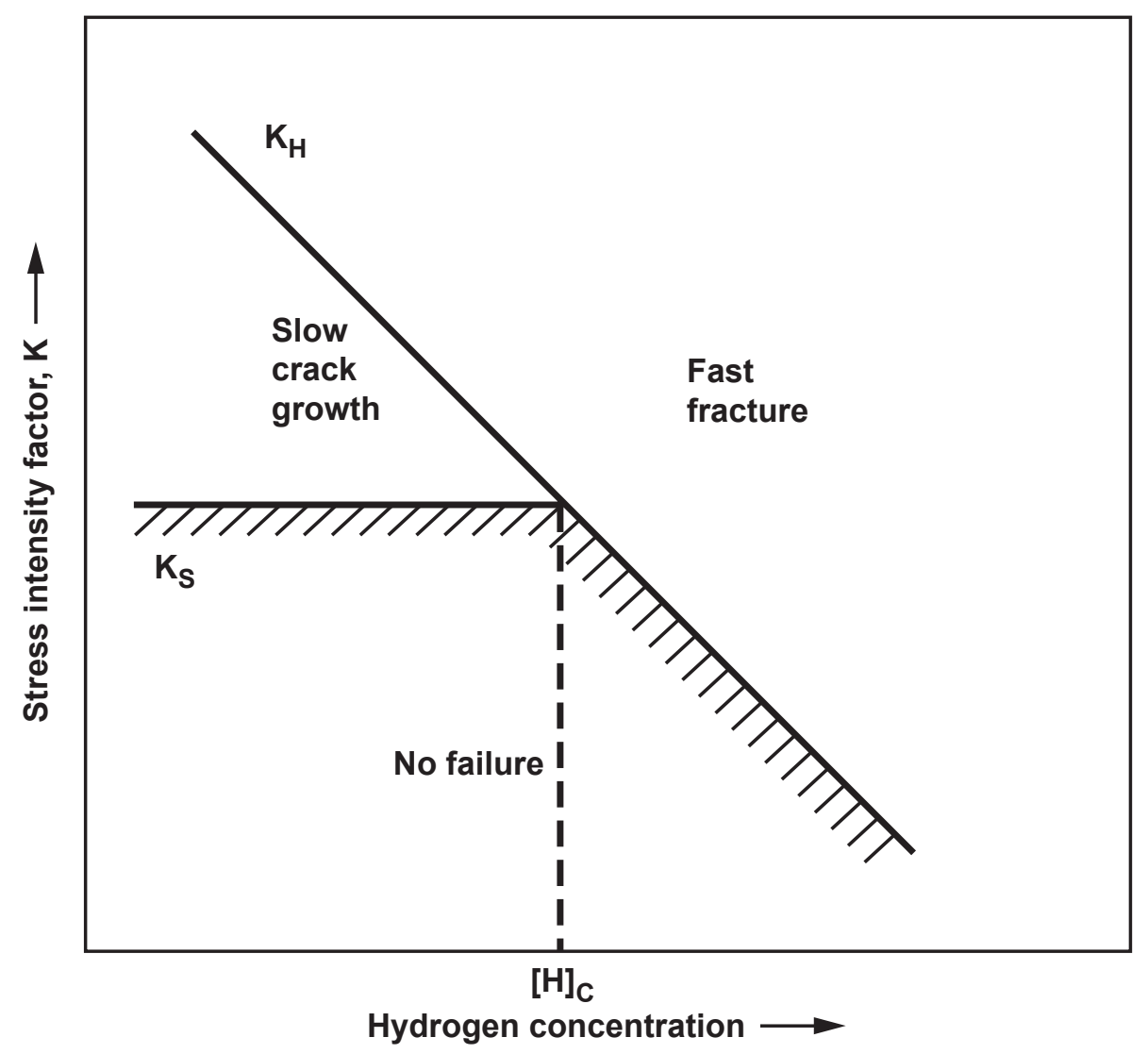

$1+1$

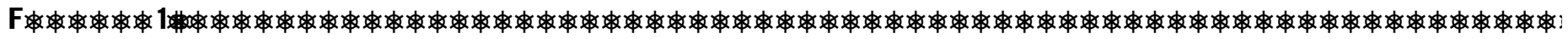

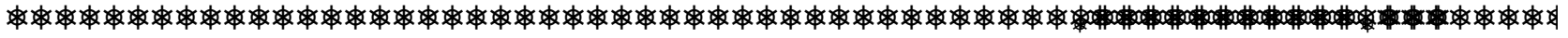

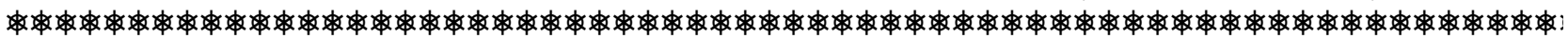

Clearly, the propagation of a localized corrosion process, whether it be a pit, a crevice, a stress corrosion crack or a hydrogen-induced crack, does not proceed instantaneously to failure. However, if the rate of propagation is fast on the geologic time scales being considered then the process can be thought of as instantaneous; e.g., 30 years of "slow" crack growth is irrelevant on a time scale of $10^{3}$ to $10^{5}$ years. Another factor ignored in this analysis is the impact of propagation-limiting processes. For example, with a pit or crevice, repassivation may occur; or with a stress corrosion crack, crack blunting could occur. In the HIC model described below, no crack initiation or crack blunting processes are considered.

The model can best be described as follows:

1. The passive oxide is assumed to be permeable to hydrogen.

2. Hydrogen is generated at the surface of the Ti alloy. This is described by a hydrogen generation rate, which is taken to be equal to the rate of the general passive corrosion rate. 
3. A fraction of the hydrogen is absorbed into the oxide and assumed to directly enter the alloy. The remainder combines to yield hydrogen gas, which is lost to the surroundings. The rate of absorption is taken to be directly proportional to the hydrogen generation rate multiplied by an absorption efficiency coefficient.

4. Once in the alloy, the hydrogen is transported throughout the entire thickness of the material to yield a uniform distribution of hydrogen. In other words, transport processes within the alloy are rapid compared to the rate of absorption.

5. The hydrogen content of the alloy is allowed to increase until a critical level is reached. The material then fails immediately.

Below, the rationale and some of the implications of adopting such a model are discussed.

\section{The oxide is assumed to be permeable to hydrogen.}

Within a Canadian waste vault, this is a point for discussion. However, under Yucca Mountain conditions, the case that the oxide is permeable is much harder to make, and hence the probability of hydrogen absorption occurring is much lower. In this context, the term probability is used loosely and descriptively.

In a Canadian waste vault, the repository is sealed and the only available oxidants are those trapped on sealing, redox conditions will eventually evolve to anoxic conditions. When all available $\mathrm{O}_{2}$ is effectively consumed, the redox conditions at the Ti waste container surface will be sustained by the reaction with trivial amounts of oxidizing impurities in the vault, or, in their absence, by reaction with water. Under these conditions, the corrosion potential of the container (waste package) surface will decrease.

Providing faults do not exist in the passive oxide on the waste package surface, the package remains impermeable to hydrogen until the electrical potential becomes sufficiently negative that the oxide becomes chemically unstable. Once this occurs, $\mathrm{Ti}^{\mathrm{IV}}$ within the $\mathrm{TiO}_{2}$ oxide is reduced to $\mathrm{Ti}^{\mathrm{III}}$, and hydrogen can be incorporated as a doping defect. (The chemistry/electrochemistry of this transformation has been discussed in Shoesmith et al. (1997)). Once this process becomes possible it is conservatively assumed that the oxide becomes permeable to hydrogen, which then has free access to the alloy; i.e., any hydrogen entering the oxide can be rapidly transported to the metal.

Several mitigating factors indicate that this is a very conservative scenario. First, experimental evidence (Shoesmith 1999) suggests that total permeability is not established as soon as this oxide transformation begins. Second, it is difficult to imagine that, in the absence of specific reducing reagents, such redox transformations could be induced in the passive film. Experimental observations show this threshold for the introduction of permeability to be as low as $-0.6 \mathrm{~V}$ [vs. saturated calomel electrode (SCE)] in neutral solutions at $30^{\circ} \mathrm{C}$ (Murai et al. 1977).

Counterbalancing the above factors are the influences of temperature and alloying additions to the Ti. For temperatures above $\sim 70^{\circ} \mathrm{C}$, crystallization of the passive oxide could introduce faults and grain boundaries that would facilitate the transport of hydrogen through the oxide. The 
alloying elements, such as nickel (Ni) (Ti-12) and palladium (Pd) (Ti-16 and Ti-7), act as catalysts for proton reduction. Their presence as intermetallic particles in the alloy could introduce faults in the oxide ("hydrogen windows") leading to the possibility of hydrogen absorption at potentials more positive than the threshold value described above. This scenario could lead to the absorption of hydrogen at potentials attainable under open-circuit anoxic corrosion conditions. Evidence exists with Ti-12 and Ti-7 that this "sub-threshold" absorption of hydrogen can occur under electrochemical conditions; i.e., in the presence of an applied polarization. This process does not appear to occur with Ti-16, although the reason for this is unknown. Consequently, under anoxic waste vault/repository conditions, the possibility of hydrogen adsorption by these alloys must be considered.

However, Yucca Mountain will not achieve anoxic conditions. In the early stages of vault lifetime, when temperatures are high, the oxygen content of the vault will be low, but so will the water content, which is the only significant potential source of hydrogen (due to reaction with the Ti). Eventually, oxidizing conditions will be established and an open-circuit corrosion potential, too positive to allow the redox transformations in the oxide, will be established. Also, for oxidizing conditions, any exposed noble metal intermetallic particles (e.g., $\mathrm{Ti}_{2} \mathrm{Ni}$ in $\mathrm{Ti}-12, \mathrm{Ti}_{\mathrm{x}} \mathrm{Pd}$ in Ti-16/Ti-7) will be passivated by a surface oxide film, and their catalytic properties for hydrogen production and absorption will be lost.

The possibility exists that between the states of a hot, dry, low-oxygen condition and a cooler, wet, oxygenated condition, a warm, extremely saline solution of unpredictable $\mathrm{pH}$ could exist on the Ti surface. This $\mathrm{pH}$ could conceivably rise as high as 14 . There is a concern that hydrogen absorption could occur in this environment, and, indeed, the prospect cannot definitely be ruled out. However, available industrial experience indicates this is a remote possibility.

Assuming that the maximum temperature at which an aqueous condition can be sustained on the Ti is $125^{\circ} \mathrm{C}$, a $\mathrm{pH}>13$ would be required for significant hydrogen absorption (see Figure 31, Schutz and Thomas, 1987). It would be judicious to assume, therefore, that hydrogen absorption is possible within the temperature range of $\sim 100^{\circ} \mathrm{C}$ to $125^{\circ} \mathrm{C}$. This range effectively defines a "window of susceptibility" for hydrogen absorption.

The probability of hydrogen absorption by Ti alloys at Yucca Mountain is low, but cannot be ruled out within the window of susceptibility defined by the temperature range of $100^{\circ} \mathrm{C}$ to $125^{\circ} \mathrm{C}$.

\section{Hydrogen is generated at the surface of the titanium alloy.}

The only feasible source of absorbable hydrogen appears to be the reaction of Ti with water. The direct absorption of radiolytically produced hydrogen requires a combination of high dose rate $\left(>10^{4} \mathrm{R} / \mathrm{h}\right)$ and high temperature $\left(>200^{\circ} \mathrm{C}\right)$ (Shoesmith and King 1999) and a steam or aqueous environment. This combination of conditions seems extremely unlikely at Yucca Mountain. Under open-circuit conditions, the rate of hydrogen production will be directly related to the general corrosion rate. In the presence of dissolved oxygen this rate has been shown to be extremely low, and effectively immeasurable by standard procedures such as weight change measurements. Consequently, the rate of hydrogen production (the essential model boundary 
condition) will also be extremely low. Swedish workers reached similar conclusions (Mattsson and Olefjord 1990, Mattsson et al. 1990).

However, noble metal/alloy intermetallics could be catalysts for water reduction, leading to enhanced corrosion of the Ti and production of hydrogen. Under anoxic vault conditions, this is a significant consideration. However, under oxic conditions it will not lead to a significant enhancement of general corrosion; the process will be blocked by the excellent protective properties of the passive $\mathrm{TiO}_{2}$ film. Also, under oxic conditions, the intermetallics should be covered by a passive oxide film and their catalytic properties severely degraded.

As discussed above, for the temperature range $100^{\circ} \mathrm{C}$ to $125^{\circ} \mathrm{C}$, some enhanced absorption of hydrogen may be possible. However, it is not sufficient that the Ti surface, or the intermetallics within it, possess catalytic cathodic properties. No cathodic process can occur without a simultaneous anodic process. Therefore, the passive oxide formed along with the hydrogen must be of sufficiently poor quality that anodic oxide growth can continue. This process seems extremely unlikely on the Pd-containing alloys, because continued oxide growth $\left(\right.$ as $\left.\mathrm{TiO}_{2}\right)$ would lead to the eventual ennoblement of the alloy as Pd concentrated in the alloy surface (Shoesmith 1999). On Ti-12, evidence suggests that, in extremely saline solutions, enhanced film growth accompanied by hydrogen absorption is sustainable, at least for a few years (see papers by Oriani in Shoesmith and King, 1999).

Under Yucca Mountain conditions the corrosion rate of Ti alloys (with the possible exception of Ti-12), and, hence, the rate of hydrogen production, will most likely be slow and transitory. Evidence suggests that even when corrosion, in the form of film growth, is initially accelerated under oxic conditions, the accumulation of mineral precipitates leads to the eventual blocking of the corrosion process (Pan et al. 1996).

\section{A fraction of the hydrogen is absorbed into the metal.}

Even if the oxide film present on the $\mathrm{Ti}$ surface provides just a semipermeable barrier to hydrogen absorption into the metal, only a fraction of the hydrogen produced will actually be absorbed into the metal, and hence contribute to the eventual embrittlement of the alloy. The question is, what is the value of this fraction? A consistent single value may not represent the real absorption efficiency of the alloy because this efficiency would be expected to change as the condition of the surface changed. The initial surface could be relatively free of absorbed hydrogen and the initial absorption efficiency could be high. ${ }^{*}$ Subsequently, it would be expected to decrease as the number of available surface sites for absorption become saturated. These absorption sites could be the usual defects and dislocations known to trap hydrogen and, in addition, noble metal intermetallic particles, which would have a high solubility for hydrogen. Alternatively, the formation of surface hydrides could lead to a change in the mechanism of proton reduction and a decrease in the rate of hydrogen absorption into the alloy. Evidence supports these views, but consistent, usable values of the efficiency remain to be measured.

\footnotetext{
* All Ti alloys contain a certain amount of hydrogen in the absorbed state. This hydrogen is widely distributed and present in the form of precipitated hydrides.
} 
Two extreme values of the efficiency of absorption are available (Shoesmith 1999). Okada (1983) measured the efficiency electrochemically as a function of $\mathrm{pH}$ for Ti, Ni-plated Ti, and Pd-plated Ti. For $\mathrm{pH}>3.5$, the efficiency for all these systems was $\leq 5 \%$ ( $\sim 5 \%$ for Ni-plated, $\sim 2 \%$ for $\mathrm{Ti}$ ). These values seem appropriate for passive neutral conditions and could be considered conservative, since the Ti-alloy structure used at Yucca Mountain would not be noble-metal-coated.

However, the concern remains that, in the temperature range $100^{\circ} \mathrm{C}$ to $125^{\circ} \mathrm{C}$, in the presence of an aggressive saline solution, the passive oxide will be degraded and the hydrogen absorption efficiency increased. There are two sources for an absorption efficiency value. Oriani (1989a and 1989b) measured both the film growth rate (i.e., the rate of hydrogen production) and the hydrogen absorption rate for Ti-12 in extremely saline solutions at $25^{\circ} \mathrm{C}$ and at $\mathrm{T}>100^{\circ} \mathrm{C}$. These values would be appropriate for degraded passive conditions, because they closely resemble those anticipated at Yucca Mountain. Noel et al. (1996) measured absorption efficiencies in simulated crevice solutions and obtained values between $5 \%$ and $15 \%$. The latter value could be taken as an upper value for the efficiency because it was measured in actively propagating crevices at temperatures in excess of $100^{\circ} \mathrm{C}$. Consequently, Noel et al. (1996) values are very conservative when used for passive conditions.

\section{Once in the metal the hydrogen is transported throughout the entire thickness of the material to yield a uniform distribution.}

Once hydrogen is in the metal its fate becomes dependent on the diffusion rate, and how that rate is affected by the microstructure of the material and the strength and distribution of stresses within the material. Developing a model incorporating all these variables would be complex, and it would be difficult to test. A major drawback would be a complete lack of knowledge of the strength and distribution of stresses. Consequently, no attempt was made to deal with these features within a model.

It was assumed that, because the rate of absorption of hydrogen into the metal would be very slow, its transport throughout the bulk of the material would be comparatively rapid. Hence, the hydrogen would be uniformly distributed throughout the alloy. At the very much higher absorption rates generally found during the electrochemical experiments, absorbed hydrogen lead to the formation of a surface hydride layer (Noel et al. 1996). Such a layer is commonly observed industrially at potentials in the region of $-1.0 \mathrm{~V}$ (vs. SCE) (applied for cathodic protection or achieved due to galvanic coupling to carbon steel) and is innocuous, not leading to failure by cracking. The presence of such a layer appears to impede the absorption of further hydrogen; i.e., its presence reduces the absorption efficiency of the alloy.

If the absorption rate is slow relative to the transport rate, then calculating the uniform distribution of hydrogen is assumed to be simple. This approach was used in the Canadian model (Shoesmith et al. 1995). If the absorption rate is sufficiently high to cause the formation of a surface hydride layer, then it can be treated as a layer growth in the same manner one would consider an oxide film growth; i.e., as a general passive corrosion process. The rate of formation of this layer could be calculated from the hydrogen generation rate multiplied by the absorption efficiency according to the following reaction: 
$\mathrm{Ti}+2 \mathrm{H}_{2} \mathrm{O} \rightarrow \mathrm{TiH}_{2}+2 \mathrm{OH}^{-}$

According to Phillips et al. (1972) The composition of this hydride is in the range $\mathrm{TiH}_{1.21}$ to $\mathrm{TiH}_{1.48}$. The amount of hydrogen absorbed could be expressed as a surface layer thickness, and considered as "lost" wall thickness as one would do for a general corrosion process. This may be the best way to view hydrogen absorption in the susceptible range between $100^{\circ} \mathrm{C}$ and $125^{\circ} \mathrm{C}$.

However, this hydrogen accumulates at the Ti surface. A conservative assumption is that it remains available for transport into the alloy. Consequently, once the temperature is low enough that the transport rate can be assumed to exceed the absorption rate $\left(<100^{\circ} \mathrm{C}\right)$, then this layer will lose thickness as the hydride is redissolved in the alloy at the hydride/alloy interface; i.e., the "stored" surface hydrogen now acts as an input boundary condition for transport and accumulation of hydrogen in the bulk of the material. From this point on the hydride redissolves until it is gone and the transport rate then becomes equal to the absorption rate.

\section{The hydrogen content of the material is allowed to increase until a critical level is reached and failure occurs.}

The slow strain rate tests (Shoesmith et al. 1997 and references therein) show that titanium can tolerate substantial amounts of hydrogen before it becomes susceptible to cracking. This critical hydrogen concentration is not related to the solubility of hydrogen in the alpha matrix of the alloy, but to the number density of precipitates, which must be capable of supporting a crack propagation process through the material. Values for this critical hydrogen concentration are given in Shoesmith (1999) for Ti-2, Ti-12 and Ti-16 (preliminary value). The high value for Ti-16 ( $>1,000 \mu \mathrm{g} / \mathrm{g})$ appears to be due to the ability of the intermetallics to soak up hydrogen, thereby preventing them from forming hydride precipitates in the alloy.

Whichever model is assumed for the dispersion of hydrogen throughout the Ti alloy, failure is assumed to occur once this critical value is achieved. However, this remains a very conservative approach because slow strain rate tests have determined the point at which the necessary stress level will inevitably be achieved. Also, the critical value is a threshold value, representing the lowest concentration at which any influence of hydrogen is observed. It is quite feasible that much higher concentrations of hydrogen could be tolerated before failure actually occurs.

\subsection{APPLICATION OF HIC MODEL TO DRIP SHIELD}

\subsubsection{Material}

Titanium Grade 7 (Ti-7) [UNS R52400] is now being considered for construction of the drip shield for the waste package. Based on Pasupathi (1999), this alloy consists of $0.3 \% \mathrm{Fe}, 0.25 \%$ $\mathrm{O}, 0.12-0.25 \% \mathrm{Pd}, 0.1 \% \mathrm{C}, 0.03 \% \mathrm{~N}, 0.015 \% \mathrm{H}, 0.4 \%$ total residuals, with the balance being Ti.

\subsubsection{Determination of the Critical Hydrogen Concentration, $\mathrm{H}_{\mathrm{C}}$}

Using the slow strain rate technique on precracked compact tension specimens precharged with known amounts of hydrogen, it has been shown that the fracture toughness of Ti-2 and Ti-12 is not significantly affected until their hydrogen content exceeds a critical value, $\mathrm{H}_{\mathrm{C}}$. The 
as-received materials, containing 20 to $50 \mu \mathrm{g} / \mathrm{g}$ of hydrogen, are very tough, and fail by ductile overload under high stress. This ductile tearing is also observed during slow-crack growth for both materials. The $\mathrm{H}_{\mathrm{C}}$ is the hydrogen concentration above which slow-crack growth is no longer observed and only fast-crack growth occurs. This behavior is schematically presented in Figure 1.

In accordance with Shoesmith (1999), Sorensen (1990) and coworkers have demonstrated that the alloy Ti-12 requires a hydrogen content of $>500 \mu \mathrm{g} / \mathrm{g}$ before any measurable loss of ductility occurs. Shoesmith (1999) also reported that, based on test results reported in Shoesmith et al. (1997), values of $\mathrm{H}_{\mathrm{C}}$ of 500 to $800 \mu \mathrm{g} / \mathrm{g}$ for Ti-2 and 400 to $600 \mu \mathrm{g} / \mathrm{g}$ for Ti-12 have been determined. More recent measurements (Ikeda, unpublished data) show that hydrogen for Ti-16 is at least $1,000 \mu \mathrm{g} / \mathrm{g}$, and may be much greater. $\mathrm{H}_{\mathrm{C}}$ data are not available for Ti-7. The $\mathrm{H}_{\mathrm{C}}$ value for Ti-7 is assumed to be at least $400 \mu \mathrm{g} / \mathrm{g}$, which is the lower bound value observed for Ti-2, Ti-12, and Ti-16, as indicated above.

\subsubsection{Determination of Hydrogen Concentration}

The effect of controlled electrochemical potential on the absorbed hydrogen concentration analyzed by secondary ion mass spectrometry (SIMS) for Ti-7 and Ti-12 was observed by Roy et al. (1999). The slow strain rate test (SSRT) technique was used, and the tests were performed in a deaerated $90^{\circ} \mathrm{C}$ acidic brine $(\mathrm{pH} \cong 2.7)$ containing 5 weight percent sodium chloride $(\mathrm{NaCl})$ using a strain rate of $3.3 \times 10^{-6} \mathrm{sec}^{-1}$. Figure 6 of Roy et al. (1999), which summarizes the test results, is reproduced as Figure 2 below. The test data in Figure 2 indicate that the concentration of hydrogen in both Ti-7 and Ti-12 was increased with more cathodic applied potential. These results may also suggest that the amount of hydrogen generated in these alloys as a result of potentiostatic polarization at comparable cathodic potentials was not significantly influenced by their chemical compositions. The basic difference in composition between these two alloys is that Ti-7 contains palladium (Pd) while Ti-12 is alloyed with molybdenum (Mo) and nickel (Ni). Figure 2 also indicates that the hydrogen concentration does not exceed $180 \mathrm{ppm}(\mathrm{or} \mu \mathrm{g} / \mathrm{g})$ in the controlled potential range.

Data reported by Bedrossian (1999) for SIMS analyses of crevice coupons tested at the Long Term Corrosion Test Facility (LTCTF) of LLNL show hydrogen content inside the crevices, relative to measurements taken outside the crevices and to an uncorroded control. Test coupons of Ti-12 and Ti-16 were tested under various combinations of different conditions of temperature $\left(90^{\circ} \mathrm{C}\right.$ and $\left.60^{\circ} \mathrm{C}\right)$, environment (simulated concentrated water $(\mathrm{SCW})$ and simulated dilute water (SDW)), and phases (vapor and aqueous). A typical result is illustrated by Figure 3, which shows the SIMS depth profiles for hydrogen in Ti-16 specimen tested under $90^{\circ} \mathrm{C}$, SDW, and aqueous phase after one year. This figure shows that the hydrogen content is below the critical hydrogen concentration $(1,000 \mu \mathrm{g} / \mathrm{g})$, except in the crevices near the surface, and the hydrogen content drops very quickly to the tens $\mu \mathrm{g} / \mathrm{g}$ level at about $10^{4} \stackrel{\mathrm{O}}{\mathrm{A}}$ from the surface. Although the data reported by Bedrossian (1999) are not qualified, they present a better than qualitative indication of low hydrogen pick-up by titanium materials. 


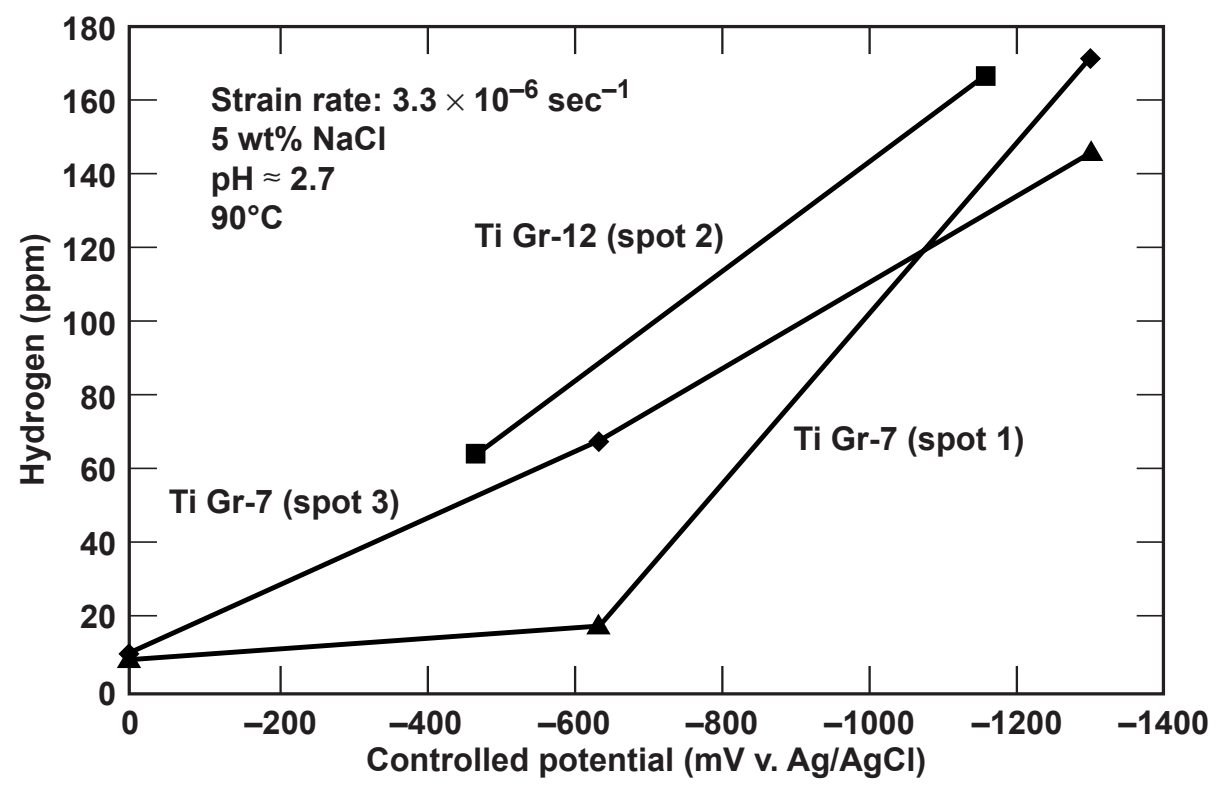

16

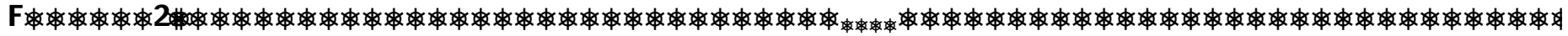
\$1999

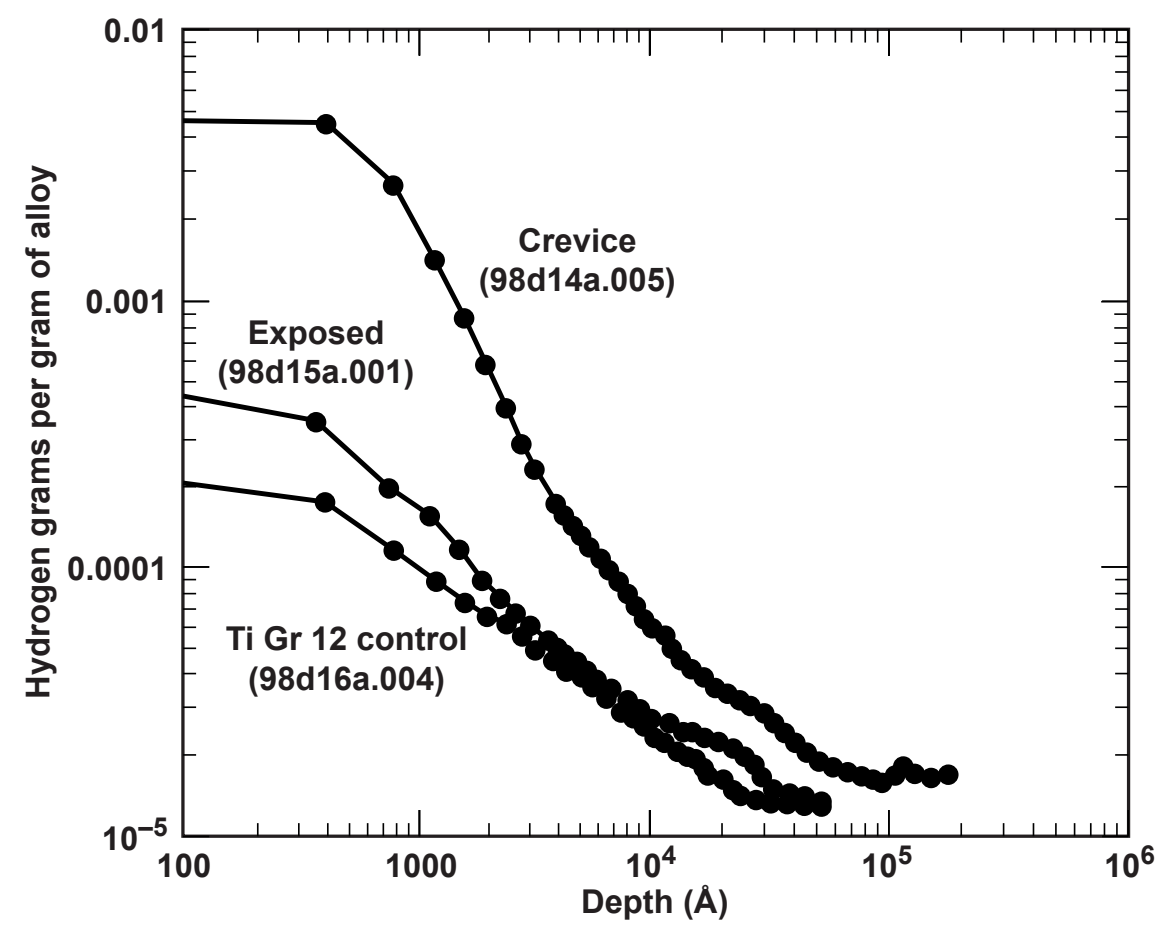

16

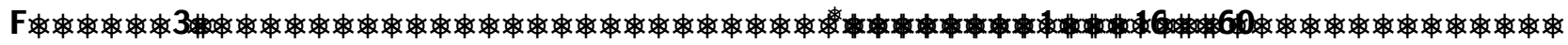

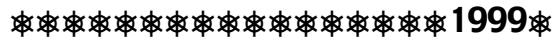




\subsubsection{Results}

In the description of the HIC model presented in Section 6.1, extensive evidence has been provided to support a qualitative assessment of Ti-7 as an excellent choice of material for the drip shield with regard to degradation caused by hydrogen-induced cracking. LTCTF test data observed at LLNL, although unqualified, provided additional indication beyond a qualitative level that hydrogen concentration appears to be low in titanium materials.

Quantitative evaluation based on the HIC model described in Section 6.1 indicates that the drip shield material (Ti-7) is able to sustain the effects of hydrogen-induced cracking. Available test data show that the hydrogen concentration is below $180 \mu \mathrm{g} / \mathrm{g}$, which is less than the critical hydrogen concentration of $400 \mu \mathrm{g} / \mathrm{g}$ for Ti-7. 


\section{CONCLUSIONS}

A simple and conservative model has been developed to evaluate the effects of hydrogeninduced cracking on the drip shield. The basic premise of the model is that failure will occur once the hydrogen content exceeds a certain limit or critical value, $\mathrm{H}_{\mathrm{C}}$. This model is very conservative because it assumes that, once the environmental and material conditions can support that particular corrosion process, failure will be effectively instantaneous. In the description of the HIC model presented in Section 6.1, extensive evidence has been provided to support a qualitative assessment of Ti-7 as an excellent choice of material for the drip shield with regard to degradation caused by hydrogen-induced cracking. LTCTF test data observed at LLNL, although unqualified, provides additional indication beyond a qualitative level that hydrogen concentration appears to be low in titanium materials.

Quantitative evaluation based on the HIC model described in Section 6.1 indicates that the hydrogen concentration does not exceed the critical value. It is concluded that drip shield material (Ti-7) is able to sustain the effects of hydrogen-induced cracking. 
INTENTIONALLY LEFT BLANK 


\section{REFERENCES}

Bedrossian, P.J. 1999. Analysis of One-Year, Titanium Coupons from Long-Term Corrosion Testing. Livermore, California: Lawrence Livermore National Laboratory, UCRL Report (to be published).

CRWMS M\&O 1999a. Classification of the Preliminary MGDS Repository Design. p. VI-11.

CRWMS M\&O 1999b. Neutronics Methodology - SR.

CRWMS 1999c. Uncanistered Spent Nuclear Fuel Disposal Container System Description Document (CRWMS 1999).

DOE 1999. Quality Assurance Requirements and Description.

Mattsson, H. and Olefjord, I. 1990. "Analysis of Oxide Formed on Ti during Exposure in Bentonite Clay-I. The Oxide Growth.” Werkstoffe und Corrosion, 41. 383-390.

Mattsson, H. and Olefjord, I. 1990. "Analysis of Oxide Formed on Ti during Exposure in Bentonite Clay-II. The Structure of the Oxide." Werkstoffe und Corrosion, 41. 578-584.

Murai T. M.; Ishikawa, M.; and Miura, C. 1977. "Absorption of Hydrogen and Titanium under Cathodic Polarization.” Boshoku Gijutsu, 26, 177-183.

Noel, J. J.; Bailey, M. G.; Crosthwaite, J. P.; Ikeda, B. M.; Ryan, S. R.; and Shoesmith, D. W. 1996. Hydrogen Absorption by Grade-2 Titanium. Atomic Energy of Canada Ltd. Report AECL-11608. COG-96-249.

Okada, T. 1983. "Factor Influencing the Cathodic Charging Efficiency of Hydrogen by Modified Titanium Electrodes.” Electrochimica Acta, 28(8), 1113-1120 (1983).

Oriani. 1989a. Corrosion, 43 (85-91). (1989).

Oriani. 1989b. Corrosion, 43 (92-97). (1989).

Pan, Thierry, and Leygraf. 1996. J. Biomedical Materials. Res. 30. 393-402.

Pasupathi, V. 1999. Waste Package Material Properties. CRWMS Report BBA000000-017170210-00017 REV 00, February 23, 1999.

Phillips, I. I.; Poole, P.; and Shrier, L. L. 1972. "Hydride Formation During Cathodic Polarization of Ti - Effect of Current Density on Kinetics of Growth and Composition of Hydride." Corrosion Science (12). 855-866.

Roy, A. K.; Spragge, M. K.; Flaming, D. L.; and Lum, B. Y. 1999. Cracking of Titanium Alloys under Cathodic Applied Electrochemical Potential. Livermore, California: Lawrence Livermore National Laboratory. UCRL Report. (to be published). 
Schutz, R. W. and Thomas, D. E. 1987. "Corrosion of Titanium and Titanium Alloys.” Metals Handbook. Ninth Edition. Vol. 13. Corrosion. 669-706.

Shoesmith, D. W. 1999. Review of the Expected Behaviour of Alpha Titanium Alloys under Yucca Mountain Conditions. Report to US DOE.

Shoesmith, D. W. and King, F. 1999. The Effects of Gamma Radiation on the Corrosion of Candidate Materials for the Fabrication of Nuclear Waste Packages. Atomic Energy of Canada Ltd. Report AECL-11999.

Shoesmith, D. W.; King, F.; and Ikeda, B. M. 1995. An Assessment of the Feasibility of Indefinite Containment of Canadian Nuclear Fuel Wastes. Atomic Energy of Canada Ltd., Report AECL-10972, COG-94-534.

Shoesmith, D. W.; Hardie, D.; Ikeda, B. M.; and Noel, J. J. 1997. Hydrogen Absorption and the Lifetime Performance of Titanium Waste Containers. Atomic Energy of Canada Ltd.

Report AECL-11770, COG-97-035-I.

Sorensen, N. R. 1990. "Laboratory Studies of the Corrosion and Mechanical Properties of Titanium Grade-12 under WIPP Repository Conditions." Corrosion of Nuclear Fuel Waste Containers. Workshop Proceedings. Winnipeg, February 9-10, 1988, 29-44. Edited by D. W. Shoesmith. Atomic Energy of Canada Ltd. Report AECL-10121. 


\title{
9. ATTACHMENTS
}

\author{
Attachment Title \\ I Document Input Reference Sheet
}




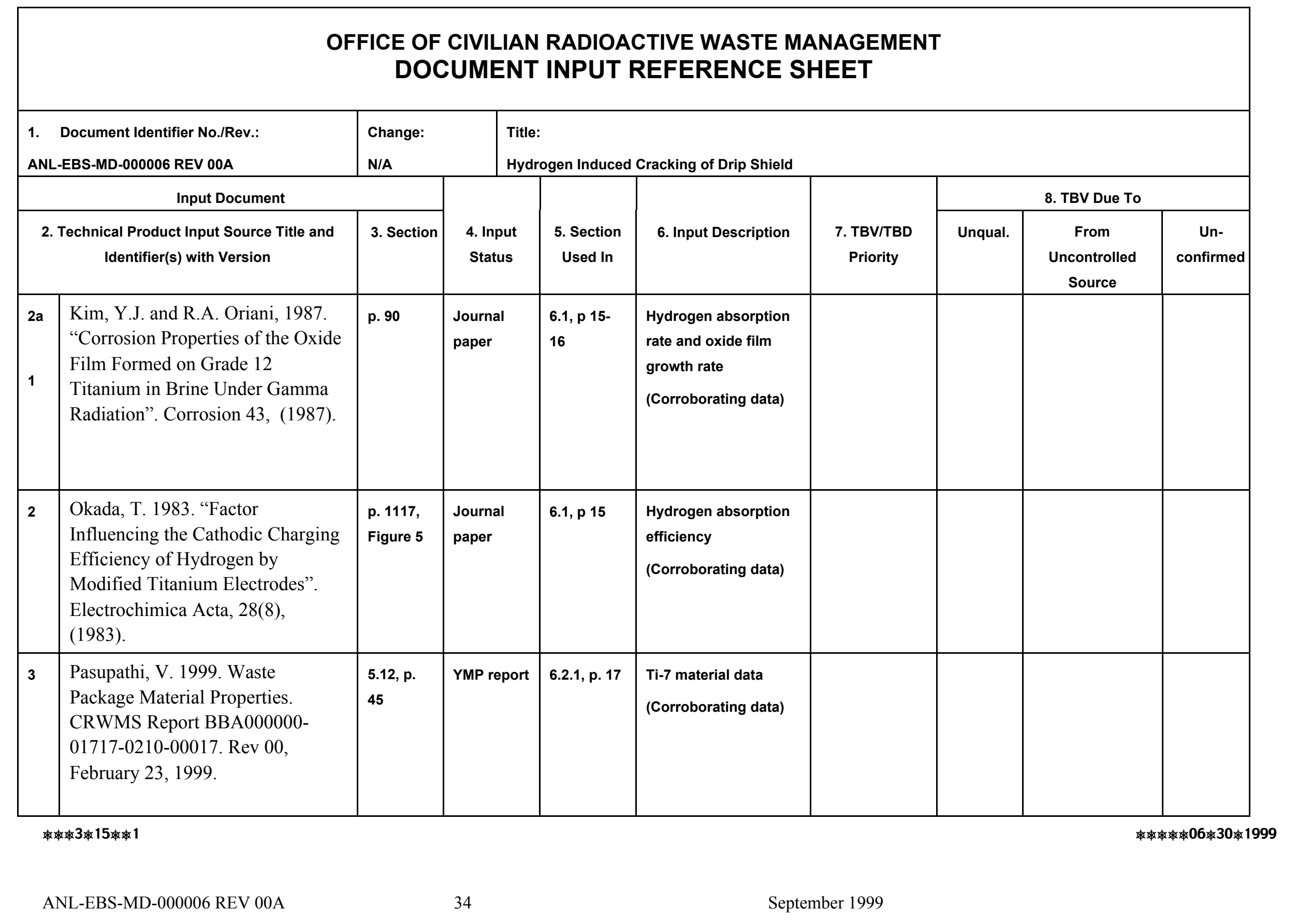




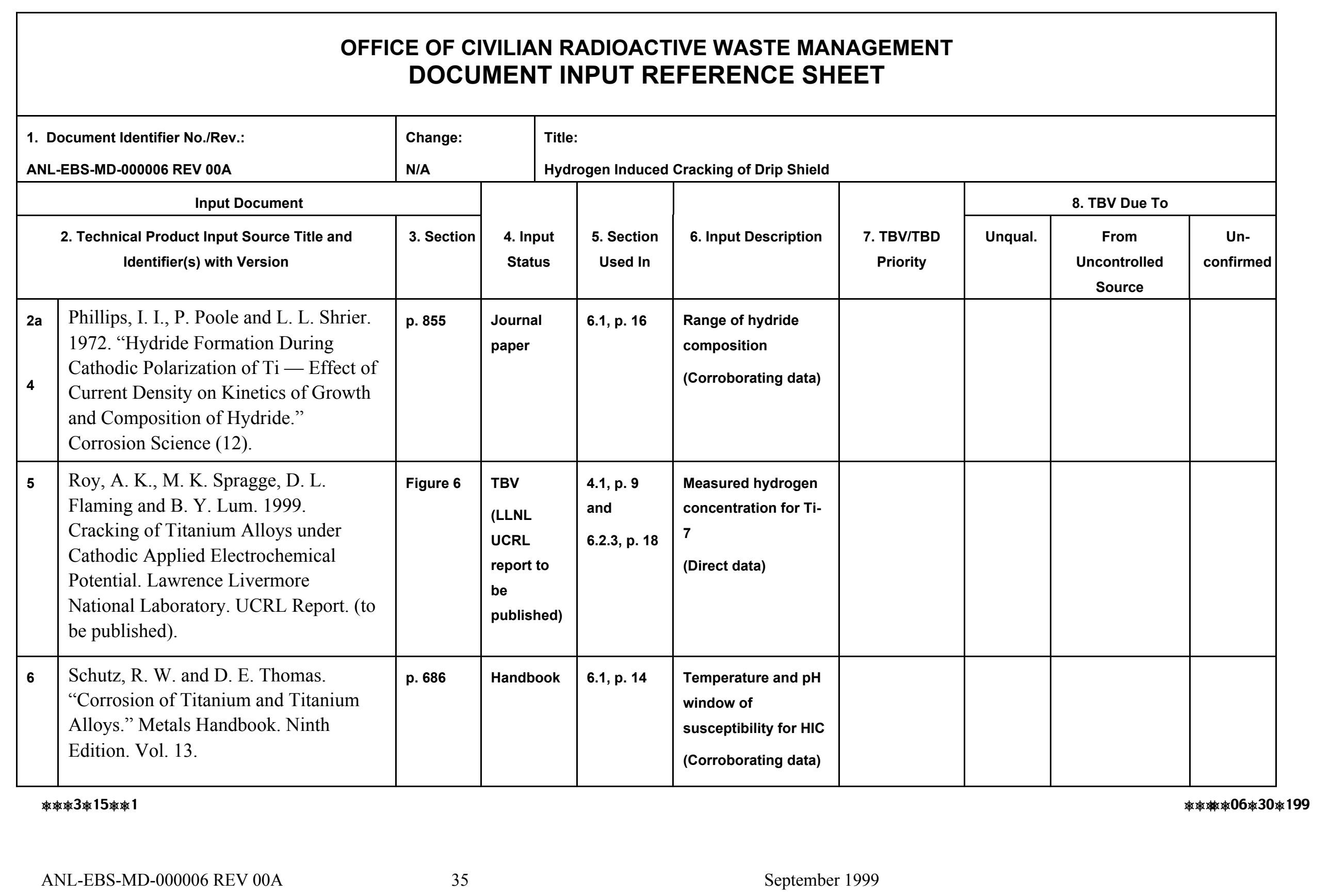




\begin{tabular}{|c|c|c|c|c|c|c|c|c|c|}
\hline \multicolumn{10}{|c|}{$\begin{array}{l}\text { OFFICE OF CIVILIAN RADIOACTIVE WASTE MANAGEMENT } \\
\text { DOCUMENT INPUT REFERENCE SHEET }\end{array}$} \\
\hline \multicolumn{2}{|c|}{$\begin{array}{l}\text { 1. Document Identifier No./Rev.: } \\
\text { ANL-EBS-MD-000006 REV 00A }\end{array}$} & $\begin{array}{l}\text { Change: } \\
\text { N/A }\end{array}$ & & \multicolumn{6}{|c|}{$\begin{array}{l}\text { Title: } \\
\text { Hydrogen Induced Cracking of Drip Shield }\end{array}$} \\
\hline \multicolumn{3}{|c|}{ Input Document } & \multirow[b]{2}{*}{$\begin{array}{l}\text { 4. Input } \\
\text { Status }\end{array}$} & \multirow[b]{2}{*}{$\begin{array}{l}\text { 5. Section } \\
\text { Used In }\end{array}$} & \multirow[b]{2}{*}{ 6. Input Description } & \multirow[b]{2}{*}{$\begin{array}{l}\text { 7. TBV/TBD } \\
\text { Priority }\end{array}$} & \multicolumn{3}{|c|}{ 8. TBV Due To } \\
\hline & $\begin{array}{l}\text { echnical Product Input Source Title } \\
\text { and Identifier(s) with Version }\end{array}$ & 3. Section & & & & & Unqual. & $\begin{array}{l}\text { From } \\
\text { Uncontrolled } \\
\text { Source }\end{array}$ & $\begin{array}{l}\text { Un- } \\
\text { confirmed }\end{array}$ \\
\hline \multicolumn{10}{|c|}{$2 a$} \\
\hline 7 & $\begin{array}{l}\text { Shoesmith, D. W. } 1999 . \\
\text { Review of the Expected } \\
\text { Behaviour of Alpha Titanium } \\
\text { Alloys under Yucca Mountain } \\
\text { Conditions. Report to US } \\
\text { DOE. }\end{array}$ & $\begin{array}{l}\text { p. } 17 \\
\text { p. } 59 \\
\text { p. } 78\end{array}$ & $\begin{array}{l}\text { TBV } \\
\text { (YMP } \\
\text { report) }\end{array}$ & $\begin{array}{l}4.1, \text { p. } 9 \\
6.1, \text { p. } 17 \\
6.2 .2, \text { p. } 17 \\
6.1 \text {, p. } 13 \\
6.1 \text {, p. } 15\end{array}$ & $\begin{array}{l}\text { Critical hydrogen } \\
\text { concentration } \\
\text { (Direct data) } \\
\text { Hydrogen absorption rate } \\
\text { (Corroborating data) } \\
\text { Hydrogen absorption } \\
\text { efficiency } \\
\text { (Corroborating data) }\end{array}$ & & & & \\
\hline 8 & $\begin{array}{l}\text { Shoesmith, D. W., D. Hardie, } \\
\text { B. M. Ikeda and J. J. Noel. } \\
\text { 1997. Hydrogen Absorption } \\
\text { and the Lifetime Performance } \\
\text { of Titanium Waste Containers. } \\
\text { Atomic Energy if Canada Ltd. } \\
\text { Report AECL-11770, COG- } \\
\text { 97-035-I. }\end{array}$ & $\begin{array}{l}\text { p. } 9 \\
\text { p. } 3 \\
2.1, \text { p. } 7\end{array}$ & $\begin{array}{l}\text { Technical } \\
\text { report }\end{array}$ & $\begin{array}{l}6.1, \text { p. } 11 \\
6.1, \text { p. } 13 \\
6.1, \text { p. } 17\end{array}$ & $\begin{array}{l}\text { HIC model description } \\
\text { (Corroborating data) } \\
\text { Chemistry/electrochemistry } \\
\text { transformation } \\
\text { (Corroborating data) } \\
\text { Slow strain rate tests } \\
\text { (Corroborating data) } \\
\text { Hydrogen concentration } \\
\text { determination } \\
\text { (Corroborating data) }\end{array}$ & & & & \\
\hline
\end{tabular}

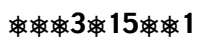

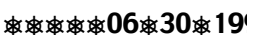

